\title{
Faktor-faktor yang Berhubungan dengan Keterlambatan Kedatangan Pasien Stroke di RSUP Prof. Dr. R. D. Kandou Manado
}

\author{
${ }^{1}$ Derrel V. Barahama \\ ${ }^{2}$ Gilbert Tangkudung \\ ${ }^{2}$ Mieke A. H. N. Kembuan
}

\author{
${ }^{1}$ Program Studi Pendidikan Dokter Fakultas Kedokteran Universitas Sam Ratulangi Manado \\ ${ }^{2}$ Bagian Ilmu Penyakit Saraf Fakultas Kedokteran Universitas Sam Ratulangi Manado \\ RSUP Prof. Dr. R. D. Kandou Manado \\ Email: 15011101072@student.unsrat.ac.id
}

\begin{abstract}
Stroke is a global health problem. Ensuring the arrival of patients to the hospital to get medical treatment in a timely manner is vital in a stroke event. The late arrival of stroke patients at the hospital is the main reason for delayed medical treatment. Age, gender, education level, site of residence, distance of residence, and ambulance usage are some of the factors associated with the late arrival of stroke patients to the hospital. This study was aimed to determine the relationship between age, gender, educational status, distance of residence, residence site, as well as ambulance usage and the late arrival of stroke patients at Prof. Dr. R. D. Kandou Hospital Manado. This was an analytical retrospective study using patients' medical record data. Samples were obtained by using purposive sampling technique with a minimum number of 226 samples. Data were analyzed by using the chi-square test which showed that of the 231 samples the $P$ values were, as follows: age $(P=0.711)$, gender $(P=0.879)$, education level $(P=0.010)$, residence site $(P=0.303)$, distance of residence $(P=0.458)$, and ambulance usage $(P=0.469)$. Conclusion: There was a significant association between education level and the late arrival of stroke patients at Prof. R. D. Kandou Hospital Manado.
\end{abstract}

Keywords: stroke, late arrival

\begin{abstract}
Abstrak: Stroke merupakan masalah kesehatan global. Memastikan kedatangan pasien ke rumah sakit untuk mendapatkan penanganan medis secara tepat waktu merupakan hal yang vital pada suatu kejadian stroke. Keterlambatan kedatangan pada pasien stroke sebelum tiba di rumah sakit merupakan alasan utama terjadinya keterlambatan penanganan medis pada kasus stroke. Usia, jenis kelamin, tingkat pendidikan, jarak tempat tinggal, letak tempat tinggal dan pengguanaan ambulans merupakan beberapa faktor yang berhubungan dengan keterlambatan kedatangan pasien stroke ke rumah sakit. Penelitian ini bertujuan untuk mengetahui hubungan antara usia, jenis kelamin, tingkat pendidikan, letak tempat tinggal, jarak tempat tinggal dan penggunaan ambulans dengan keterlambatan kedatangan pasien stroke di RSUP Prof. dr. R. D. Kandou Manado. Jenis penelitian ialah analitik retrospektif menggunakan data rekam medik pasien. Metode pengambilan sampel menggunakan teknik purposive sampling dengan jumlah minimal 226 sampel yang memenuhi kriteria penelitian. Hasil uji chi-square dari 231 sampel mendapatkan nilai $P$ sebagai berikut: usia $(P=0,711)$, jenis kelamin $(P=0,879)$, tingkat pendidikan $(P=0,010)$, letak tempat tinggal $(P=0,303)$, jarak tempat tinggal $(P=0,458)$ dan penggunaan ambulans $(P=0,469)$. Simpulan: Terdapat hubungan bermakna antara tingkat pendidikan dengan keterlambatan kedatangan pasien stroke di RSUP Prof. R. D. Kandou Manado
\end{abstract}

Kata kunci: stroke, keterlambatan kedatangan 
Stroke merupakan kumpulan gejala klinis defisit neurologis baik fokal maupun global yang mendadak dan progresif, dengan gejala berlangsung selama 24 jam atau lebih atau menyebabkan kematian, tanpa penyebab lain yang jelas selain vaskuler. ${ }^{1,2}$

Stroke merupakan masalah kesehatan global. Menurut data WHO tahun 2016 stroke merupakan penyebab kematian dan disabilitas nomor dua di dunia. ${ }^{3}$ Stroke menempati posisi kedua setelah penyakit jantung sebagai penyakit penyebab kematian di Indonesia. ${ }^{3}$ Menurut hasil laporan Riset Kesehatan Dasar (Riskesdas) 2013, prevalensi stroke berdasarkan diagnosis tenaga kesehatan (nakes) tertinggi di Sulawesi Utara $(10,8 \%)^{2}{ }^{2}$

Kedatangan pasien stroke yang lebih awal ke rumah sakit memberikan kesempatan pada pasien untuk mendapatkan penanganan medis yang cepat dan tepat, yang berhubungan dengan keberhasilan terapi dan perbaikan luaran klinis pasien, sedangkan luaran klinis akan mengalami perburukan pada pasien stroke yang tidak mendapatkan penanganan medis secara cepat dan tepat. ${ }^{4}$

Keterlambatan kedatangan pada pasien stroke sebelum tiba di rumah sakit merupakan alasan utama terjadinya keterlambatan terapi pada kasus stroke. ${ }^{5}$

Salah satu faktor yang berhubungan dengan keterlambatan kedatangan pasien stroke di rumah sakit ialah kurangnya pengetahuan mengenai gejala dan tanda stroke. $^{4}$

Penelitian yang dilakukan di Cina pada 62 rumah sakit tahun 2006 menyatakan bahwa terdapat hubungan antara usia pasien $\geq 65$ tahun dengan kedatangan pasien lebih awal di rumah sakit. Hal tersebut diduga terjadi akibat kesadaran pada pasien ( $\geq 65$ tahun) akan gejala stroke yang lebih tinggi karena merupakan target kampanye promosi kesehatan. $^{6}$

Studi observasional yang dilakukan di Korea Selatan terhadap 6636 pasien di 23 Departemen Kegawatgaruratan Rumah Sakit sepanjang tahun 2008, ditemukan bahwa waktu kedatangan pasien ke rumah sakit secara bermakna lebih panjang pada perempuan. Pada studi ini keterlambatan pada CT Scan atau MRI sejak onset gejala stroke pada perempuan teridentifikasi berhubungan dengan keterlambatan kedatangan pasien ke Departemen Kegawatdaruratan Rumah Sakit sejak terjadinya onset gejala stroke. $^{7}$

Penelitian yang dilakukan di India selama periode Januari 2012 sampai Desember 2012 mendapatkan bahwa tingkat pendidikan pasien yang lebih tinggi berhubungan dengan kedatangan pasien ke rumah sakit lebih awal. Hasil analisis univariat pada penelitian yang sama menyatakan bahwa jarak tempat tinggal pasien yang lebih dekat dengan rumah sakit merupakan salah satu faktor yang berhubungan dengan kedatangan pasien lebih awal ke rumah sakit. ${ }^{8}$

Tingkat pendidikan yang rendah pada pasien stroke berhubungan dengan keterlambatan kedatangan pasien ke rumah sakit. Hal ini dapat dijelaskan oleh karena kurangnya pengetahuan pasien mengenai tingkat keparahan gejala stroke. ${ }^{5}$

Hasil penelitian yang dilakukan di Riyadh, Arab Saudi pada bulan November 2012 sampai April 2013, mendapatkan letak tempat tinggal merupakan salah satu faktor yang bermakna dalam keterlambatan kedatangan pasien stroke ke Departemen Kegawatgaruratan Rumah Sakit. Pasien yang tinggal di luar kota Riyadh cenderung terlambat untuk datang ke rumah sakit dan pasien yang sendirian atau tidak memiliki pendamping saat onset stroke terjadi lebih cenderung terlambat untuk datang ke rumah sakit. Penelitian tersebut menyatakan bahwa pasien yang datang menggunakan ambulans sebagai pilihan transportasi ke rumah sakit, berhubungan dengan kedatangan pasien yang lebih awal untuk mendapatkan terapi. ${ }^{9}$

Penelitian ini bertujuan untuk mengetahui faktor-faktor yang berhubungan dengan keterlambatan kedatangan pasien stroke di RSUP Prof. Dr. R. D. Kandou Manado.

\section{METODE PENELITIAN}

Jenis penelitian ini ialah analitik retro- 
spektif menggunakan data rekam medik pasien stroke yang dirawat di RSUP Prof. Dr. R. D. Kandou Manado. Pengambilan sampel pada penelitian ini menggunakan teknik purposive sampling. Data rekam medis pasien stroke iskemik dan stroke hemoragik yang terdapat keterangan waktu terjadinya gejala stroke, waktu kedatangan pasien di rumah sakit dan data demografis pasien yaitu; usia, jenis kelamin, tingkat pendidikan, letak tempat tinggal, jarak tempat tinggal, dan data penggunaan ambulans pasien lengkap diambil sebagai sampel. Jumlah minimal sampel yaitu 226 sampel, diambil berdasarkan rumus Lameshow dengan menggunakan populasi pada penelitian sebelumnya. ${ }^{10}$

Data yang diperoleh dianalisis dengan uji chi-square dan disajikan dalam bentuk tabel. Waktu kedatangan, yang menjadi variabel tergantung, merupakan waktu dari awal terjadinya gejala stroke sampai waktu saat pasien tiba di rumah sakit sesuai data rekam medis, dibagi menjadi terlambat $(>24$ jam) atau tidak terlambat $(\leq 24$ jam). Usia ( $<65$ atau $\geq 65$ tahun), jenis kelamin (laki-laki atau perempuan), tingkat pendidikan (rendah: tidak tamat SMA; tinggi: tamat SMA), letak tempat tinggal (Manado atau luar Manado), jarak tempat tinggal $(\leq 25 \mathrm{~km}$ atau $>25 \mathrm{~km})$ dan penggunaan ambulans (ya atau tidak), merupakan variabel-variabel bebas.

\section{HASIL PENELITIAN}

Berdasarkan pengumpulan data rekam medik di Bagian Rekam Medik RSUP Prof. Dr. R. D. Kandou Manado, didapatkan 231 berkas rekam medik pasien dengan stroke pada tahun 2017 yang berjumlah 155 dan berkas rekam medik pasien tahun 2016 yang berjumlah 76 . Jumlah ini lebih besar dari jumlah sampel minimal yang diperlukan, yaitu 226 sampel.

\section{Karakteristik Subjek Penelitian}

Karakteristik subyek berdasarkan jenis stroke (Tabel 1), yaitu 134 dari 231 (58\%) pasien didiagnosis sebagai stroke hemoragik dan 97 pasien (42\%) didiagnosis stroke iskemik.
Tabel 1. Karakteristik subyek berdasarkan tipe stroke

\begin{tabular}{lcc}
\hline Tipe stroke & Jumlah & $(\boldsymbol{\%})$ \\
\hline Iskemik & 97 & 42 \\
Hemoragik & 134 & 58 \\
Total & 231 & 100 \\
\hline
\end{tabular}

Tabel 2 menunjukkan karakteristik subyek berdasarkan waktu kedatangan pasien di rumah sakit dengan jumlah yang terlambat sebanyak 112 dari $231(48,5 \%)$ pasien dan yang tidak terlambat 119 pasien $(51,5 \%)$.

Tabel 2. Karakteristik subyek berdasarkan waktu kedatangan

\begin{tabular}{lcc}
\hline Tipe stroke & Jumlah & $(\boldsymbol{\%})$ \\
\hline Terlambat & 112 & 48,5 \\
Tidak terlambat & 119 & 51,5 \\
Total & 231 & 100 \\
\hline
\end{tabular}

Tabel 3 memperlihatkan bahwa pasien stroke lebih sering dijumpai pada usia $<65$ tahun yaitu 165 orang $(71,4 \%)$ dibandingkan pada usia $\geq 65$ tahun yaitu 66 orang $(28,6 \%)$. Pasien stroke dengan jenis kelamin laki-laki lebih banyak yaitu 131 orang $(56,7 \%)$ dibandingkan dengan jenis kelamin perempuan yaitu 100 orang $(43,3 \%)$. Stroke paling sering terjadi pada pasien dengan tingkat pendidikan SMA yaitu 144 orang $(61,9 \%)$, lebih tinggi dibandingkan dengan SMP yaitu 45 orang $(18,6 \%)$, tingkat pendidikan SD yaitu 25 orang $(10,8 \%)$, tingkat pendidikan sarjana yaitu 11 orang $(4,8 \%)$, dan tidak ada tingkat pendidikan yaitu 9 orang $(3,9 \%)$. Pasien stroke dengan letak tempat tinggal berada di luar Manado mempunyai jumlah yang lebih banyak yaitu 166 orang (71,9\%), dibandingkan dengan pasien stroke yang letak tempat tinggalnya berada di Manado yaitu 65 orang $(28,1 \%)$. Jarak tempat tinggal pasien stroke dengan persentase tertinggi pada jarak $>25 \mathrm{~km}$ yaitu 120 orang $(52 \%)$, sedangkan tempat tinggal pasien stroke pada jarak tempat tinggal $\leq 25$ km sebanyak 111 orang (48\%). Distribusi pasien stroke yang tidak menggunakan 
ambulans yaitu 184 orang $(79,65 \%)$, lebih banyak dibandingkan dengan pasien stroke yang menggunakan ambulans sebagai pilihan transportasi ke rumah sakit yaitu 47 orang $(20,35 \%)$.

Hasil analisis menggunakan uji chi square antara variabel bebas dan variabel tergantung yaitu, usia $(P=0,771)$, jenis kelamin $(P=0,879)$, letak tempat tinggal $(P=0,303)$, jarak tempat tinggal $(P=0,458)$, dan penggunaan ambulans $(P=0,469)$. Nilai $P>0,05$ menunjukkan bahwa tidak terdapat hubungan bermakna antara usia, jenis kelamin, letak tempat tinggal, jarak tempat tinggal, dan penggunaan ambulans dalam penelitian ini. Hasil pengujian dengan uji chi square antara waktu kedatangan dengan tingkat pendidikan mendapatkan nilai $P=0,010$ yang menandakan bahwa terdapat hubungan bermakna antara tingkat pendidikan dan keterlambatan kedatangan pasien stroke di RSUP Prof. Dr. R. D. Kandou Manado.

Tabel 3. Hasil analisis antara variabel bebas dan variabel tergantung

\begin{tabular}{lcc}
\hline & Total $(\boldsymbol{\%})$ & $\boldsymbol{P}$ \\
\hline Usia & 231 & 0,771 \\
$<65$ Tahun & $165(71,4)$ & \\
$\geq 65$ Tahun & $66(28,6)$ & \\
Jenis kelamin & 231 & 0,879 \\
$\quad$ Laki-Laki & $131(56,7)$ & \\
Perempuan & $100(43,3)$ & \\
Tingkat pendidikan & 231 & 0,010 \\
Tinggi (tamat SMA) & $155(67,1)$ & \\
Rendah (tidak tamat SMA) & $76(32,9)$ & \\
Letak tempat tinggal & 231 & 0,303 \\
Manado & $65(28,1)$ & \\
Luar Manado & $166(71,9)$ & \\
Jarak tempat tinggal & 231 & 0,458 \\
$\quad \leq 25$ kilometer & $111(48)$ & \\
$>25$ kilometer & $120(52)$ & \\
Penggunaan ambulans & 231 & 0,469 \\
Ya & $47(20,35)$ & \\
Tidak & $184(79,65)$ & \\
\end{tabular}

\section{BAHASAN}

Hasil analisis univariat dari data memperlihatkan bahwa persentase pasien dengan tipe stroke hemoragik (58\%) lebih banyak daripada pasien dengan tipe stroke iskemik (42\%). Hasil tersebut tidak sejalan dengan teori yang menyatakan bahwa persentase tipe stroke iskemik (87\%) lebih banyak daripada tipe stroke hemoragik $(13 \%) .{ }^{11}$ Hal ini dapat disebabkan karena berkas rekam medik pasien stroke tipe iskemik selama tahun 2017 yang ditemukan peneliti hanya berjumlah 22 berkas.

Pada penelitian ini tidak didapatkan hubungan bermakna antara keterlambatan kedatangan pasien stroke di rumah sakit dengan usia. Beberapa penelitian sebelumnya melaporkan bahwa usia mempunyai hubungan bermakna dengan kedatangan pasien stroke yang lebih awal ke rumah sakit. ${ }^{12,13}$ Penelitian yang dilakukan di Cina melaporkan bahwa pasien stroke yang berusia $\geq 65$ tahun memiliki hubungan dengan kedatangan lebih awal di Instalasi Gawat Darurat. Hal tersebut mungkin disebabkan kesadaran akan gejala dan tanda stroke yang lebih tinggi, karena pasien stroke yang berusia $\geq 65$ tahun 
menjadi sasaran promosi kesehatan. ${ }^{6}$

Berdasarkan hasil uji chi square didapatkan bahwa tidak terdapat hubungan bermakna antara keterlambatan kedatangan pasien ke rumah sakit dengan jenis kelamin. Penelitian yang dilakukan di 15 rumah sakit di wilayah Greater Cicinnati/ Northern Kentucky selama tahun 2010 juga mendapatkan bahwa hubungan jenis kelamin dengan waktu kedatangan pasien stroke (khususnya stroke iskemik) ke Instalasi Gawat Darurat rumah sakit tidak berbeda secara bermakna dengan kategori usia atau tingkat keparahan stroke. Perbedaan waktu kedatangan pada pasien stroke sesuai jenis kelamin pasien kemungkinan merupakan akibat dari kurangnya kemampuan peneliti untuk mengontrol variabelvariabel yang ada dan penggunaan kriteria seleksi pasien yang berbeda-beda pada setiap penelitian. ${ }^{13}$

Hasil analisis bivariat menunjukkan bahwa terdapat hubungan bermakna antara tingkat pendidikan dengan keterlambatan kedatangan pasien stroke ke rumah sakit. Hal tersebut selaras dengan penelitian yang dilakukan di India, yaitu pasien stroke yang mempunyai tingkat pendidikan tinggi cenderung memiliki durasi keterlambatan kedatangan di rumah sakit yang lebih singkat. ${ }^{8}$ Tingkat pendidikan merupakan salah satu faktor independen penting pada pasien dengan pengetahuan tentang stroke yang adekuat. ${ }^{14}$ Pengetahuan tentang gejala dan tanda stroke yang adekuat merupakan salah satu faktor independen yang berhubungan dengan kedatangan pasien stroke yang lebih awal di rumah sakit. ${ }^{15}$

Pada penelitian ini tidak terdapat hubungan bermakna antara keterlambatan kedatangan pasien stroke di rumah sakit dengan letak tempat tinggal (Tabel 3). Hasil ini tidak selaras dengan penelitian di Riyadh, Arab Saudi yang melaporkan bahwa letak tempat tinggal merupakan salah satu faktor bermakna yang berhubungan dengan keterlambatan kedatangan pasien stroke ke rumah sakit. Pasien yang tinggal di luar kota Riyadh cenderung terlambat datang ke rumah sakit, namun keterlambatan kedatangan pasien stroke di rumah sakit tersebut juga dipengaruhi berbagai faktor lain seperti, kondisi geografis atau apakah pasien stroke tersebut langsung menuju ke rumah sakit atau mengunjungi pusat layanan kesehatan primer lokal terlebih dahulu. ${ }^{9}$

Penelitian ini mendapatkan bahwa, tidak terdapat hubungan bermakna antara keterlambatan kedatangan pasien stroke di rumah sakit dengan jarak tempat tinggal pasien. Walaupun dalam penelitian sebelumnya yang dilakukan di India ditemukan bahwa jarak tempat tinggal pasien yang lebih dekat dengan rumah sakit merupakan salah satu faktor yang berhubungan dengan kedatangan pasien lebih awal di rumah sakit, tetapi pengetahuan pasien mengenai gejala dan tanda stroke merupakan salah satu faktor penting yang berpengaruh pada waktu kedatangan pasien stroke di rumah sakit. $^{8,15}$

Hasil analisis antara variabel tergantung dan variabel bebas (Tabel 3), menunjukkan bahwa tidak terdapat hubungan bermakna antara keterlambatan kedatangan pasien stroke di rumah sakit dengan penggunaan ambulans sebagai pilihan mode transportasi pasien. Hasil studi sebelumnya telah menyatakan bahwa penggunaan ambulans sebagai alat transportasi dapat menurunkan tingkat keterlambatan kedatangan pasien stroke di rumah sakit, ${ }^{6}$ namun pengetahuan pasien akan gejala dan tanda stroke merupakan hal yang penting ketika pasien akan mengambil keputusan untuk mendapatkan pelayanan ambulans sebagai mode transportasi ke rumah sakit.

Dalam penelitian ini terdapat keterbatasan dalam jumlah sampel data rekam medik, khususnya untuk data rekam medik pasien stroke iskemik yang tidak terdistribusi dengan baik akibat ketidaklengkapan berkas rekam medik sesuai data yang ada di Sistem Informasi Rumah Sakit RSUP Prof. Dr. R. D. Kandou Manado.

Peneliti juga menyadari bahwa penelitian ini tidak spesifik untuk meneliti faktor-faktor yang berhubungan dengan keterlambatan kedatangan pasien di rumah sakit khususnya pada salah satu tipe stroke (stroke iskemik atau hemoragik). 


\section{SIMPULAN}

Berdasarkan hasil penelitian ini dapat disimpulkan bahwa tingkat pendidikan pasien stroke secara bermakna berhubungan dengan keterlambatan kedatangan pasien di RSUP Prof. Dr. R. D. Kandou Manado sedangkan usia, jenis kelamin, letak tempat tinggal, jarak tempat tinggal dan penggunaan ambulans tidak berhubungan secara bermakna dengan keterlambatan kedatangan pasien stroke di RSUP Prof. dr. R. D. Kandou Manado.

\section{SARAN}

Disarankan untuk melakukan penelitian lanjut mengenai faktor-faktor yang berhubungan dengan keterlambatan kedatangan pasien stroke di rumah sakit secara khusus (stroke iskemik atau stroke hemoragik) dengan data yang lebih lengkap agar dapat menjadi tambahan informasi untuk dilakukan tindakan medis yang cepat dan tepat pada pasien stroke.

Diharapkan agar para tenaga kesehatan dan pemerintah dapat menyelenggarakan edukasi kepada masyarakat, agar evakuasi pasien stroke ke rumah sakit untuk penanganan medis dapat dilakukan secepatnya.

\section{DAFTAR PUSTAKA}

1. Truelsen T, Begg S, Mathers C. The Global Burden of Cerebrovascular Disease. Geneva: World Health Organization, 2006.

2. Badan Penelitian dan Pengembangan Kesehatan. Laporan Riskesdas 2013. Jakarta: Kementerian Kesehatan RI, 2013.

3. Global Health Estimates. Geneva: World Health Organization, 2018.

4. Seremwe F, Kaseke F, Chikwanha TM, Chikwasha V. Factors associated with hospital arrival time after the onset of stroke symptoms: a cross-sectional study at two teaching hospitals in Harare, Zimbabwe. Malawi Medical Journal. 2017;29(2):171-6.

5. Peixoto KO, Correa CE. Factors associated with prehospital delay in acute stroke: systematic review. Journal of Surgical and Clinical Research. 2017;8(1):1425.

6. Jin H, Zhu S, Wei JW, Wang J, Liu M, Wu
Y, et al. Factors associated with prehospital delays in the presentation of acute stroke in urban China. Stroke. 2012;43(2):362-70.

7. Park SJ, Do Shin S, Ro YS, Song KJ, Oh J. Gender differences in emergency stroke care and hospital outcome in acute ischemic stroke: a multicenter observational study. Am J Emerg Med. 2013;31(1):178-84.

8. Ashraf VV, Maneesh M, Praveenkumar R, Saifudheen K, Girija AS. Factors delaying hospital arrival of patients with acute stroke. Ann Indian Acad Neurol. 2015;18(2):162.

9. Al Khathaami AM, Mohammad YO, Alibrahim FS, Jradi HA. Factors associated with late arrival of acute stroke patients to emergency department in Saudi Arabia. SAGE Open Medicine. 2018;6:1-7.

10. Syahrizal AM. Hubungan kadar trigliserida dengan kejadian stroke iskemik di RSUD Sukoharjo [Dissertasi]. Surakarta; Universitas Muhammadiyah Surakarta; 2014.

11. Wittenauer R, Smith L. Ischaemic and haemorrhagic stroke: background paper. Geneva: WHO,, 2012.

12. Song D, Tanaka E, Lee K, Sato S, Koga M, Kim YD. Factors associated with early hospital arrival in patients with acute ischaemic stroke. Journal of Stroke 2015;17(2):159-67.

13. Madesen TE, Sucharew H, Katz B, Alwell KA, Moomaw CJ, Kissela BM, et al. Gender and time to arrival among ischaemic stroke patients in the Greater Cicinnati/Northern Kentucky Stroke Study. J Stroke Cerebrovasc Dis. 2016; 25(3): 504-10.

14. Ramírez-Moreno JM, Alonso-González R, Pacheco DP, Millán-Nuñez MV, Roa-Montero A, Constantino-Silva AB, et al. Effect of socioeconomic level on knowledge of stroke in the general population: a social inequality gradient. Neurología (English edition). 2016;31(1):24-32.

15. Koksal EK, Gazioglu S, Boz C, Can G, Alioglu Z. Factors associated with early hospital arrival in acute ischemic stroke patients. Neurological Sciences. 2014;35(10):1567-72. 